\title{
Response of Stock Returns to Oil Price Shocks: Evidence from Oil Importing and Exporting Countries
}

\author{
Jamal Bouoiyour \\ CATT, University of Pau, Pau, France \\ Refk Selmi \\ ERNA, University of Tunis El Manar, Tunis, Tunisia \& University of Pau, Pau, France \\ Syed Jawad Hussain Shahzad \\ ESD, Montpellier Business School, Montpellier, France \\ Muhammad Shahbaz \\ ESD, Montpellier Business School, Montpellier, France
}

\begin{abstract}
This paper examines the entire dependence structure of the quantile of stock return and that of oil price shocks, thereby extending the Quantile Regression to a Quantile-onQuantile Regression. Based on historical monthly data covering the period April 1994 September 2015, it was shown that there is substantial heterogeneity in the stock returns and oil price relationship across oil importing countries and oil exporting countries. We find that the stocks of oil exporters that possess large proven oil reserves, in particular, Venezuela, Russia, and Saudi Arabia are typically more responsive toward demand-side oil shocks than those of oil importers. The intensity and the extent of these responses differ depending on the different stock market conditions and the nuances of oil price movements. profitable speculation and arbitrage strategies can be built.
\end{abstract}

\footnotetext{
* Corresponding Author: Refk Selmi; Avenue du Doyen Poplawski, 64000 Pau, France, Tel: +33 0559408001, Fax: +33 0559408010, E-mail: refk.selmi@univ-pau.fr; s.refk@yahoo.fr.

Co-authors: Jamal Bouoiyour; Avenue du Doyen Poplawski, 64000 Pau, France, Tel: +33 0559408001, Fax: +33 0559408010, E-mail: jamal.bouoiyour@univ-pau.fr.

Syed Jawad Hussain Shahzad; Muhammad Shahbaz; 2300, avenue des Moulins 34185 Montpellier cedex 4, France. Tel: +3304 671025 00, Fax : +33 046745 13 56, E-mail: jawad.kazmi5@gmail.com; shahbazmohd@live.com
} 
JEL Classification: E44, G12, Q43

Keywords: Oil Price Shocks, Stock Returns, Dependence of Quantiles, Oil Exporting Countries, Oil Importing Countries

\section{Introduction}

This study attempts to test the explanatory power of global oil price shocks on stock returns of fourteen oil importer countries (China, France, Germany, India, Japan, the UK, and the US) and oil exporter countries (Canada, Kuwait, Mexico, Norway, Russia, Saudi Arabia, and Venezuela) even if we control for asymmetry. Our study is related to an emerging literature that seeks to provide a broad perspective on dependence by modeling the quantile relationship. Inspired by Sim and Zhou (2015), a Quantile-on-Quantile Regression (QQR) approach will be used to model the joint dependence of quantiles. Sim and Zhou (2015) and Bouoiyour and Selmi (2016) performed a QQR to estimate how the quantile of stock return is correlated with the quantile of oil price shock. As pointed out, the econometric framework developed in this research is based on the quantile regression paradigm. Typically, quantile regression focuses on modeling the conditional quantile of the endogenous variable, as opposed to ordinary least squares regression that models its conditional mean. We should mention that the main reason behind our departure from the standard quantile regression model is to allow the regressor to be itself a quantile. To construct the QQR technique, we first specify a system of equations having a recursive triangular structure. For the case of the bivariate QQR model, two equations are required. The first equation models the quantile of the dependent variable such as the real stock returns, conditioned on the quantile of a regressor including oil price shocks. Then, the quantile of the regressor will be separately modeled in another regression. Indeed, this approach uncovers two nuance features in the linkage between oil shocks and equity returns. By doing so, quite interesting findings have been derived from the QQR approach. We show that the nature and sensitivity of the stock returns responses to oil price shocks change substantially across tail distributions, suggesting the occurrence of asymmetry. Beyond the nuance of asymmetry, the responses of the different stock markets to oil price shocks appear highly heterogeneous. Overall, we find that oil producers react more strongly than oil importers toward oil shocks. Specifically, 
Venezuela, Russia, and Saudi Arabia, in that order, appear to be most influenced.

The past decades have seen wild swings in the oil market, causing wide-ranging ramifications for oil exporting and importing countries. The fluctuations in global growth and oil demand are one possible explanation for the largest oil price changes. Not long after the untoward oil shock of the 1970s, there was a large increase in the amount of literature concerning the effects of oil price shocks on the aggregate economy. To a lesser extent, scholars and policymakers debated over the impacts of oil shocks on equity returns and portfolio investment. Although there was a strong presumption in the financial economics literature that oil prices can satisfactorily predict stock market performances, the empirical evidence on the impact of oil price on stock returns has been inconclusive (Haung et al. 1996, Apergis and Miller 2009, Broadstock and Filis 2014). Early research such as Jones and Kaul (1996) supported the notion that oil prices can, in isolation, predict equity returns for at least the US, Canada, and Japan. Subsequent empirical studies have confirmed that oil price shocks exert a strong influence on stock markets in several developed and emerging countries. For instance, Huang et al. (1996), Sadorsky (1999), Papapetrou (2001), and Shimon and Raphael (2006) argued that oil price exerts a negative influence on equities possibly due to business operating costs and low corporate earnings. While a limited number of studies showed a positive relationship between oil price shocks and stock returns (e.g. Narayan and Narayan 2010, Ono 2011), other works provided evidence that oil price diversely affects stock returns (Maghyereh 2004, Park and Ratti 2008, Apergis and Miller 2009, Al Janabi et al. 2010, Wang et al. 2013, Bouoiyour and Selmi 2016). Recently, Jammazi and Nguyen (2015) evaluated the relationship between oil price and stock returns in a sample of oil-dependent countries and suggested that stock markets react differently to oil shocks depending on the country coverage. However, most of these studies do not make a distinction between oil importing and exporting economies.

The present study belongs to a literature that distinguishes on the equities' responses to oil price shocks between oil exporting and oil importing countries (Apergis and Miller 2009, Park and Ratti 2008, Wang et al. 2013, Le and Chang 2015). In fact, Park and Ratti (2008) analyzed the oil price-stock returns nexus for thirteen European countries and deduced that oil price shocks exert a significant and positive influence on oil exporters (e.g. Norway), whereas the opposite occurs for oil importing countries. Nevertheless, Apergis and Miller (2009), for a sample of oil importers and exporters, revealed that stock markets do not appear sensitive to oil price shocks. More recently, Wang et al. (2013) and Le and Chang (2014) disentangled oil shocks into oil supply shocks and 
aggregate demand shocks and then investigated their effects on stock returns for a mixed sample composed of oil exporting and importing countries. They found that oil shocks do not affect uniformly the concerned equities. They attributed these heterogeneous stock markets' reactions to the oil-dependence profile and the hidden factors driving oil markets.

From a methodological perspective, the multiplicity of hidden features driving the oil markets and the speculative bubbles characterizing asset has required models that allow to properly capture dynamic dependencies in data. In fact, linear correlation may not be a satisfactory measure of dependence as it does not account for dependence between tail events. Obviously, equity returns may respond to oil price shocks distinctly depending on whether the stock market is bearish or bullish. In addition, equities may react differently to larger and smaller or negative and positive oil price shocks. Therefore, the focus is no longer on the mean effect, but on the full distributions of oil price shocks and stock returns. Correlation asymmetries would ensure that market participants have the opportunity to make informed decisions. In fact, investors, traders, and policymakers attentively follow financial market evolution even if each one has dissimilar interests. Traders monitor stock markets variations to optimize the riskreturn profile while regulators employ equity prices to gather information on market expectations of economic growth and inflation. Despite the growing number of studies on the relationship between oil prices and stock markets, almost all we know regarding the strength and the extent of this linkage is for the case of oil producers. These studies used either using time series data on one country (Haung et al. 1996) or conducted crosssectional data analysis across countries (Maghyereh 2004). The global effects of oil price shocks on stock markets distinguishing between oil producers and oil importers, however, have remained relatively understudied although there are some exceptions such as Wang et al. (2013). The originality of our study lies in it.

The results show that the oil price shocks display heterogeneous linkage with stock returns, conditional on the nature of countries (i.e., oil importing or oil exporting countries), the different stock market states (bear, normal or bull) and the various kinds of oil price changes (low, normal or high).

The rest of the paper is organized as follows. Section II describes not only the methodology pursued throughout this study with a brief data overview. Section III reports the main empirical results. Section IV examines the validity of QQR analysis. Lastly, Section V concludes and offers some portfolio allocation implications. 


\section{Methodology and Data}

This section investigates the responses of stock returns to oil price shocks for a sample of countries composed of oil exporters and importers. Although data on the stock returns for all the investigated countries are available, the oil price shocks have to be estimated first. To this end, we adopt a two-step estimation procedure. The first step consists of employing the Structural Vector Auto Rregression (SVAR) approach of Kilian and Park (2009) to properly capture the structural shocks in oil prices. In the second step, we use these shocks to estimate the relationship between oil price shocks and the equities returns.

\section{A. The Oil price shocks}

We first capture the oil price shocks. Some techniques have been constructed under the assumption of strict exogeneity of oil price. This seems ineffective as there exist fundamentals that contribute jointly to stock returns and oil prices (Barsky and Kilian 2004). However, it may be appropriate to separate between demand shocks and supply shocks in the crude oil market. In this context, Kilian $(2008,2009)$ and Kilian and Park (2009) argued that demand and supply shocks could affect differently the real oil price and the US equity market. In particular, they provided evidence that oil price changes caused by oil demand shocks have wider influence on the US stock market, whereas the reaction of US equity return to oil supply shocks is often weaker. Because it is the oil demand shock that matters, it seems highly important to extract the demand-driven portion of the innovation in oil prices. For this purpose, we construct an SVAR model based on Kilian and Park's (2009) study, and dubbed the Global Oil Market Block, in order to detect the exogenous shocks to the real oil price, which is mainly driven by demand. This model constitutes a block comprising three variables, ordered according to the percent change in global crude oil production and then by a measure of real economic activity as a global aggregate demand proxy, and, ultimately, the real oil price. Let $Z_{t}$ be the vector of these three variables and the SVAR can be written as follows:

$$
A_{0} Z_{t}=\alpha+\sum_{i=1}^{p} A_{i} Z_{t-1}+\varepsilon_{t}
$$


where $\varepsilon_{t}$ is the vector of structural shocks that are assumed to be serially and mutually uncorrelated. If $e_{t}$ denotes the vector of reduced-form VAR residuals, then the structural shocks and the VAR residuals are related via $e_{t}=A_{0}^{-1} \varepsilon_{t}$. Subsequently, to determine $\varepsilon_{t}$ , we impose some structure on $A_{0}^{-1}$. Then, a triangular structure on $A_{0}^{-1}$ is explored such that the connection among the reduced-form errors $\left(e_{t}\right)$ and the structural shocks $\left(\varepsilon_{t}\right)$ is denoted as

$$
e_{t} \equiv\left(\begin{array}{l}
e_{1 t} \\
e_{2 t} \\
e_{3 t}
\end{array}\right) \equiv\left[\begin{array}{l}
1 \ldots . .0 \ldots . .0 \\
\alpha_{21} \ldots 1 \ldots 0 \\
\alpha_{31} \ldots \alpha_{32} . .1
\end{array}\right]^{-1}\left(\begin{array}{l}
\varepsilon_{1 t} \\
\varepsilon_{2 t} \\
\varepsilon_{3 t}
\end{array}\right)
$$

where $\varepsilon_{1 t}, \varepsilon_{21}, \varepsilon_{3 t}$ and are the shocks associated with global oil production, global real activity, and real crude oil price, respectively.

\section{B. The Quantile-on-Quantile approach}

Since its introduction by Koenker and Bassett (1978), quantile regression continues to be an interesting tool as it accounts for a set of regression curves that differ across various quantiles of the conditional distribution of the dependent variable. It provides a complete description of an asymmetric time series, which is one of the main characteristics of financial data. It may bring accurate information on the average dependence between variables on the one hand and between the upper and lower tails on the other (Ma and Koenker 2006). The quantile method estimates multiple ranges of change from the minimum to the maximum responses (Koenker and Xiao 2002). One shortcoming of the QR method lies in its ineffectiveness to depict dependence in its entirety (Koenker and Xiao 2006). Even though the QR approach can infer insights about the heterogeneous responses of equities to oil price shocks pertaining to different stock return quantiles, it overlooks the possibility that whether oil price is cheap or expensive could also have an effect on the way oil prices and equities are inter-linked. Hence, the QQR approach is of use when estimating two linear quantile regressions (Sim and Zhou 2015). This new econometric tool allows relating the quantile of the various equity returns with the quantile of oil price shocks; thus, the connection between them could vary at distinct points in their respective distributions. Then, each estimated quantile concerns a specific 
segment of the conditional distribution, prompting a comprehensive description of the reaction of equities to oil price shocks already identified but missed by the standard techniques.

\section{Figure 1. Efficacy of the QQR approach}

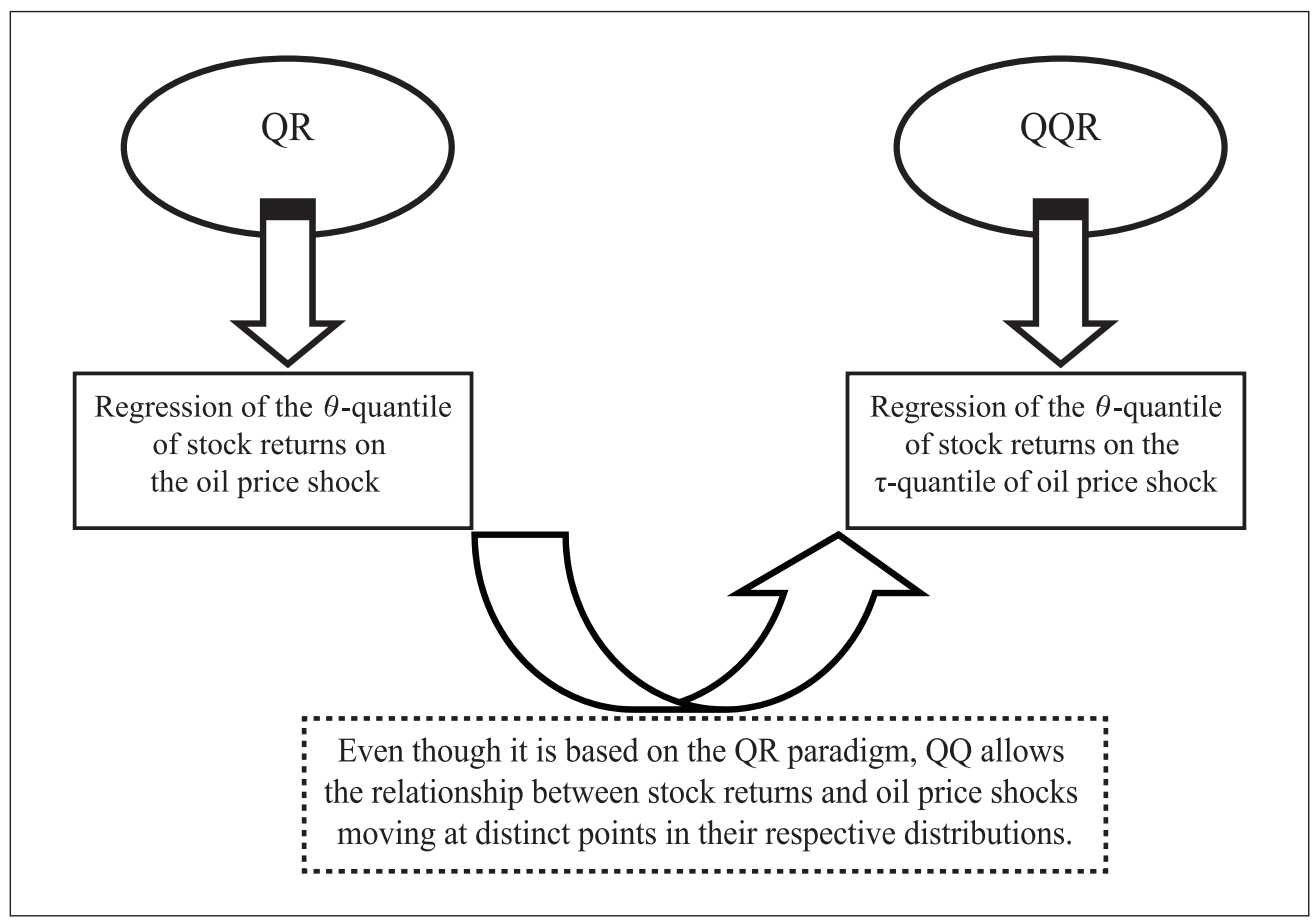

(Source) Author's own creation

Unlike QR, which regresses the $\theta$-quantile of the stock returns on oil price shocks, the QQR regresses the $\theta$-quantile of the investigated equity returns on the $\tau$-quantile of oil price shocks and, as a result, its parameters will be indexed by $\theta$ and $\tau$ (and not only by $\theta$ as in $\mathrm{QR}$ ). Therefore, one can expect that the $\mathrm{QQR}$ approach should convey more information about the focal relationship. Figure 1 briefly outlines the efficacy of QQR compared with QR.

Let the superscript STR denote the quantile of equity returns. We postulate a model for the $\theta$-quantile of $S T R$ as a function of history and oil price shocks (Oil), expressed as

$$
\operatorname{STR}_{t}=\beta^{\theta} \mathrm{Oil}_{t}+\alpha^{\theta} \operatorname{STR}_{t-1}+\varepsilon_{t}^{\theta}
$$


where $\varepsilon_{t}^{\theta}$ is an error term that has a zero $\theta$-quantile. The history of STR is used to reflect the potential exogenous variables. It allows determining the sensitivity of STR to its past values. The relationship function $\beta^{\theta}$ (.) is unknown because we have no prior insights on how STR and Oil are inter-linked. To analyze the interdependence between the $\theta$-quantile of the stock returns of the investigated oil importers and exporters and the $\tau$-quantile of oil price shocks, denoted by $O i l^{\tau}$, we linearize the function $\beta^{\theta}$ (.) by taking a first-order Taylor expansion of $\beta^{\theta}($.$) around O i l^{\tau}$, which yields

$$
\beta^{\theta}\left(\mathrm{Oil}_{t}\right) \approx \beta^{\theta}\left(\mathrm{Oil}^{\tau}\right)+\beta^{\theta^{\prime}}\left(\mathrm{Oil}^{\tau}\right)\left(\mathrm{Oil}_{t}-\mathrm{Oil}^{\tau}\right)
$$

We can redefine $\beta^{\theta}\left(O i l^{\tau}\right)$ and $\beta^{\theta^{\prime}}\left(O i l^{\tau}\right)$, respectively, as $\beta_{0}(\theta, \tau)$ and $\beta_{1}(\theta, \tau)$. Then, equation (2) can be denoted as

$$
\beta^{\theta}\left(\mathrm{Oil}_{t}\right) \approx \beta_{0}(\theta, \tau)+\beta_{1}(\theta, \tau)\left(\mathrm{Oil}_{t}-\mathrm{Oil}^{\tau}\right)
$$

Finally, we substitute equation (5) into equation (4) to obtain

$$
\operatorname{STR}_{t}=\beta_{0}(\theta, \tau)+\beta_{1}(\theta, \tau)\left(\operatorname{Oil}_{t}-\operatorname{Oil}_{\tau}\right)+\alpha(\theta) S T R_{t-1}+\varepsilon_{t}^{\theta}
$$

\section{Data}

For empirical purposes, we gauge the relationship between oil price shocks and stock returns in oil-dependent countries. Our sample data include seven oil importers (China, France, Germany, India, Japan, the UK, and the US) and seven oil exporting countries (Canada, Kuwait, Mexico, Norway, Russia, Saudi Arabia, and Venezuela). Data of stock price indices series are from April 1994 to September 2015 except for Kuwait (starts from February 2000), Russia (starts from October 1997), and Saudi Arabia (starts from November 1998). We obtain these stock market price data from the Datastream database. The Stock Return (STR) is then calculated by considering the ratio stock price (in $\log$ ) at time $t$ and the lagged stock price (in $\log$ ). Now, for the first step of our twostep procedure, we employ data on world crude Oil Production (oil production), the real crude Oil Price (oil price) as well as a measure of Global Real Economic Activity (global real economic activity). Data on the first two variables are collected from the 
US Department of Energy. Following Kilian and Park (2009) and Sim and Zhou (2015), information on global real activity is determined via an index related to a panel of Cargo Ocean shipping freight rates and based on the evidence that global aggregate demand is heavily reflected by the global demand for industrial commodities. We have transformed them by taking natural logarithms to correct for heteroscedasticity and dimensional differences. It must be mentioned that GEA is not transformed in log-returns as the index reflects changes in global economic activity.

Table 1. Descriptive statistics of the series

\begin{tabular}{|c|c|c|c|c|c|c|c|}
\hline \multicolumn{8}{|c|}{ Panel A: Oil importing countries } \\
\hline & China & France & Germany & India & Japan & $U K$ & $U S$ \\
\hline Mean & 0.0057 & 0.0028 & 0.0057 & 0.0074 & -0.0006 & 0.0025 & 0.0055 \\
\hline Maximum & 0.7955 & 0.1259 & 0.1526 & 0.2489 & 0.1582 & 0.0928 & 0.1043 \\
\hline Minimum & -0.3644 & -0.1700 & -0.2331 & -0.3312 & -0.3577 & -0.1568 & -0.1736 \\
\hline $\begin{array}{l}\text { Standard } \\
\text { deviation }\end{array}$ & 0.1035 & 0.0530 & 0.0603 & 0.0717 & 0.0627 & 0.0416 & 0.0430 \\
\hline Skewness & 1.5878 & -0.5226 & -0.9251 & -0.4369 & -0.7146 & -0.7789 & -0.8835 \\
\hline Kurtosis & 15.976 & 3.3863 & 5.0354 & 4.4954 & 6.1931 & 3.9897 & 4.5824 \\
\hline Jarque-Bera & $1918.4^{* * *}$ & $13.347^{* * *}$ & $81.337^{* * *}$ & $32.247^{* * *}$ & $131.57^{* * *}$ & $36.613^{* * *}$ & $60.484^{* * *}$ \\
\hline $\begin{array}{l}\text { Number of } \\
\text { observations }\end{array}$ & 258 & 258 & 258 & 258 & 258 & 258 & 258 \\
\hline \multicolumn{8}{|c|}{ Panel B: Oil exporting countries } \\
\hline & Canada & Kuwait & Mexico & Norway & Russia & Saudi Arabia & Venezuela \\
\hline Mean & 0.0042 & 0.0076 & 0.0110 & 0.0074 & 0.0130 & 0.0079 & 0.0361 \\
\hline Maximum & 0.1097 & 0.1841 & 0.1932 & 0.1511 & 0.4630 & 0.2386 & 0.6611 \\
\hline Minimum & -0.1991 & -0.2611 & -0.3192 & -0.3228 & -0.5228 & -0.2978 & -0.5018 \\
\hline $\begin{array}{l}\text { Standard } \\
\text { deviation }\end{array}$ & 0.0452 & 0.0543 & 0.0684 & 0.0606 & 0.1256 & 0.0759 & 0.1140 \\
\hline \multicolumn{8}{|c|}{ Panel B: Oil exporting countries } \\
\hline & Canada & Kuwait & Mexico & Norway & Russia & Saudi Arabia & Venezuela \\
\hline Skewness & -1.1033 & -0.8175 & -0.8378 & -1.5888 & -0.7495 & -0.8829 & 0.6978 \\
\hline Kurtosis & 5.9042 & 6.6152 & 5.7194 & 8.8946 & 7.2278 & 5.6746 & 7.9757 \\
\hline Jarque-Bera & $143.00 * * *$ & $123.31^{* * *}$ & $109.68^{* * *}$ & $482.07 * * *$ & $181.09^{* * *}$ & $86.879 * * *$ & $287.08 * * *$ \\
\hline
\end{tabular}


(continued)

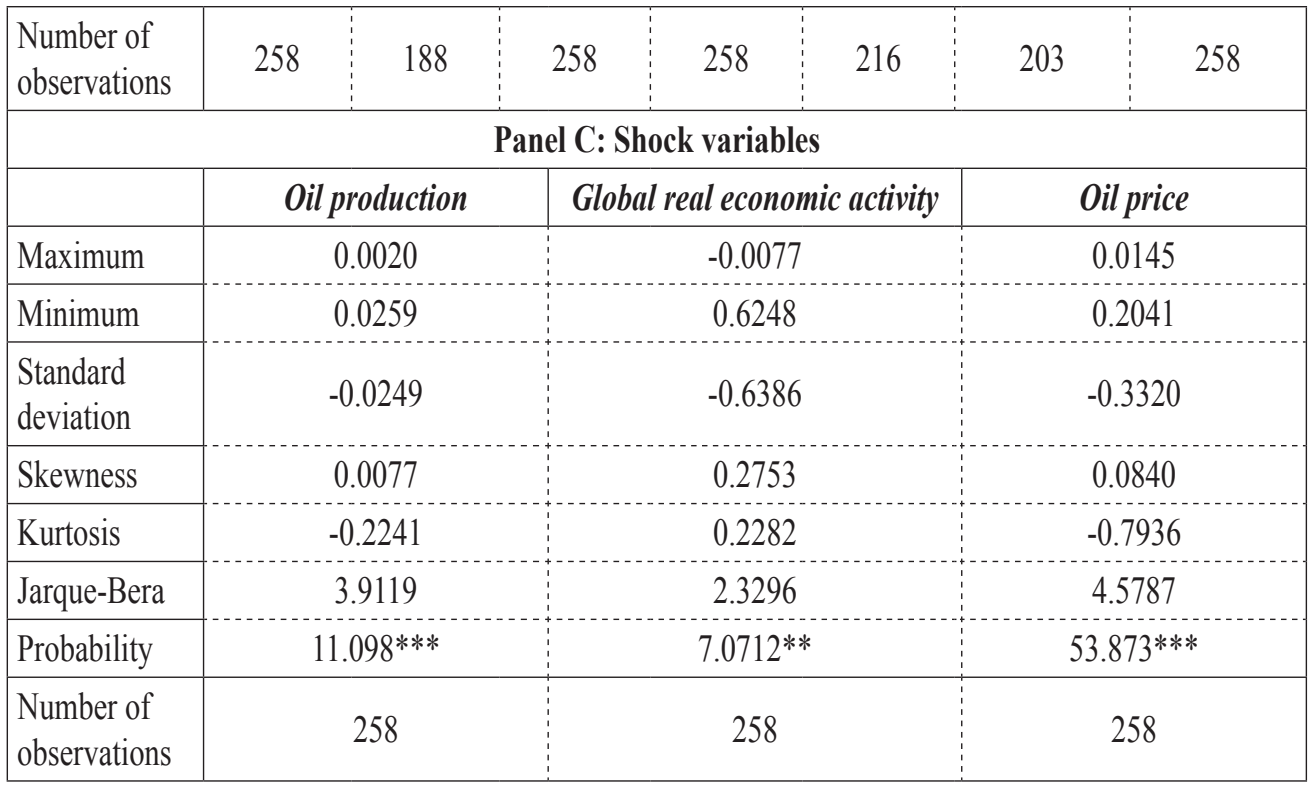

Descriptive statistics for the focal time series are reported in Table 1. Oil price shock variables (oil production, oil price, and global real economic activity) have the greatest standard deviation (Panel C, Table 1), followed by the stock returns of China for the sample of oil importers (Panel A, Table 1), and Russia and Venezuela for oil exporters (Panel B, Table 1). Skewness is negative for almost all the stock returns (except for the cases of China and Venezuela) and positive for oil price shocks. The Jarque-Bera test statistics rejects the hypothesis of normality for all cases.

\section{Results}

Before starting our QQR estimates, the first step is to construct an SVAR model in order to capture the exogenous shocks to the demand-driven oil price. Using the methodology developed by Kilian and Park (2009), we identify and compare the effects of different types of oil shocks on our sample of fourteen oil importing and exporting countries (Figure 2). We find that oil supply shocks lead to significant impacts on the variables incorporated in the model. However, the oil price shocks due to oil market- 
specific demand shifts have the strongest and mostly significant influence. Remarkably, oil shocks due to increased world real activity have variant effects: the influence appears weaker from 1994 to 2008 and then becomes more intense for the period 2009 2015.

Figure 2. Estimated oil shocks depending on their origin

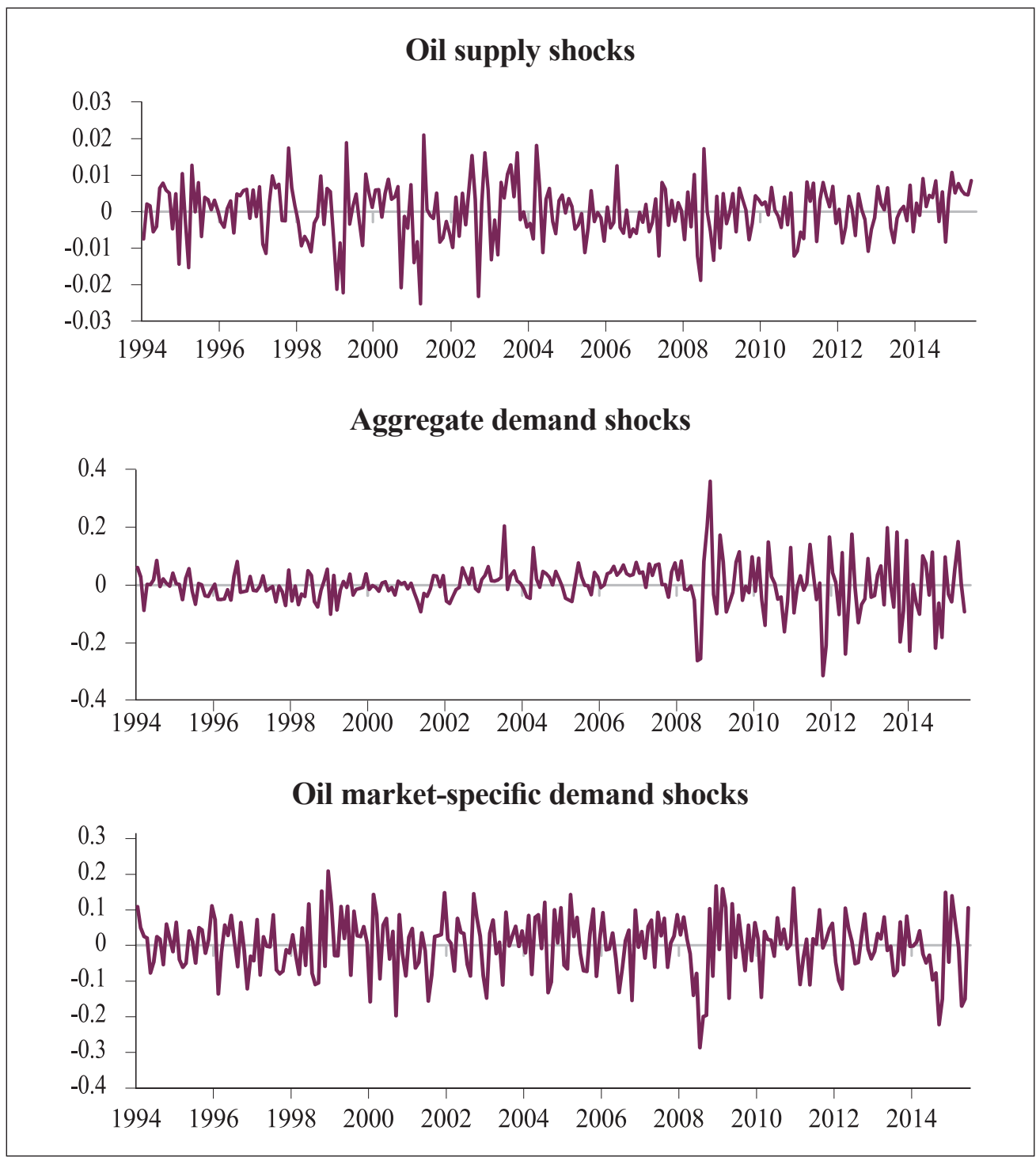

(Note) Figure 2 reflects the effects of different types of oil shocks on our sample of fourteen oil importing and exporting countries.

(Source) Model results. 
The responses to the three types of oil shocks clearly indicate that the demand channel may be the potential factor in the transmission of oil shocks to financial markets for the countries under consideration.

We perform QQR to examine the various behaviors of stock markets in response to oil price shocks. To get a sense of what these quantiles look like, Figure 3 plots the surface of the oil price's coefficient for fourteen countries: seven oil importers (Panel A, Figure 3) and seven oil exporters (Panel B, Figure 3). These graphs represent the values of the slope coefficient for different levels of and $\tau$. What appears interesting in the figure is the fact that the severity of oil price shock effects was not uniform among these investigated equities.

Let us start with the cases of oil importing countries. We distinguish two main groups of countries. The first group contains Japan, India, France, the US, and Germany (in this order), where the oil price shock exerts a strong effect on equity returns. The second group is formed by the remaining countries (i.e., China and the UK) where stock returns experienced less pronounced effect. Normally, one could expect that low oil price (i.e., low quantiles) could have a positive impact on the stock returns of oil importers. However, what we find is far from this general evidence. QQR outcomes underscore the complexity of the stock return-oil price shock nexus. For China, the relationship appears positive when the stock market is bearish (for $\theta=0.1$ ), and the oil price is low ( $\tau=0.1$ ), whereas it seems negative and much less pronounced when the stock market is functioning around its normal state $(\theta=0.5)$ and the oil price is lower (for $\tau=0.1$ and $\tau=0.2$ ). For France, a positive response of the stock returns to oil price shock is shown when the stock market is bearish $(\theta=0.1)$ and whatever the oil price level (for $\tau=0.1$, $0.2,0.3,0.4,0.5,0.6,0.7,0.8,0.9)$, whereas a negative and moderate link is found when the stock market is bullish (for $\theta=0.7,0.8,0.9)$ and the oil price is declining $(\tau=0.1$ ). For the case of Germany, we note that stock returns respond positively (negatively) to oil price shocks under bear state and when the oil price is low (under bearish and normal stock market conditions and the oil price is falling). For India, we observe a positive and significant reaction of stock returns to oil price shock under bearish stock market scenario and when the oil price is going down. For Japan, we find that there is a positive relationship between stock returns and oil price shock when both the stock market and the oil price are declining. The effect of oil shocks seems less pronounced when the oil price is high and the stock market is bearish. The UK stock returns react positively to oil price shocks when the investors are pessimistic (i.e., bearish market state) and whatever the oil price level, while they respond negatively and weakly when the stock market is 
mildly bearish $(\theta=0.3,0.4)$ and when the oil price fluctuates around the average (for $\tau=$ 0.5 ). For the US case, the stock returns are likely to be positively (negatively) correlated to oil price shocks under bearish US stock market circumstances and whatever the oil price level (when the oil price is falling and whatever the state of the US stock market).

Moreover, Figure 3 (Panel B) reports the values of the Oil coefficient for a sample of oil exporters and for different levels of $\theta$ and $\tau$. As in Panel A, Panel B is composed by two groups. The first group includes Venezuela, Russia, and Saudi Arabia (in this hierarchy), where a wider effect oil price shock on stock returns is shown. The second contains Kuwait, Norway, Mexico, and Canada, where a less intense influence is found. For Canada, we show that the relationship between Oil and STR is positive under bearish and normal states $(\theta=0.1,0.2,0.3,0.4,0.5)$ and when the oil price is low $(\tau=0.1,0.2)$. Oil's coefficient attains its peak when investors are pessimistic (i.e., bearish state; $\theta=0.1$ ) and when the oil price is low $(\tau=0.1)$ and also when it is highest $(\tau=0.9)$. In Kuwait, the stock returns reaction to oil price shock is negative and weaker when investors are optimistic (i.e., bull regime) and when oil price is lower $(\tau=0.1)$, whereas it seems significantly positive under bear stock market mode and whatever the oil price level (i.e., low, normal or high). For the Mexican case, a positive and significant STR response to Oil is seen when the stock market is bearish $(\theta=0.2)$ and the oil price is falling or fluctuating around the average $(\tau=0.1,0.2,0.3,0.4,0.5)$; Almost similarly for Norway. Focusing now on the Russian case, we note that the interdependence between oil price shock and stock return when the stock market is functioning around its bear or normal states $(\theta=0.1,0.2,0.3,0.4,0.5)$ and when the oil price is collapsing $(\tau=0.1,0.2)$. The effect of oil price shock on Russian equity appears stronger (Oil's coefficient $=2.8$ ) when the market performs skillfully $(\theta=0.1)$ and when oil price is very expensive $(\tau=0.9)$. For Saudi Arabia, the effect of oil price shock on stock return is also intense (oil shock coefficient reaches its maximum (1.8) when investors are pessimistic and oil price is high). This influence is generally significantly positive when the stock market is bearish $(\theta=0.1,0.2)$ or mildly bullish $(\theta=0.6,0.7)$ and the oil price is declining (for $\tau=0.1,0.2$, 0.3). For the case of Venezuela, we note that the response of equity return to oil price shock seems negative when investors are pessimistic $(\theta=0.1)$ and oil price is cheapest $(\tau$ $=0.1$, neutral when the equity market is modestly efficient and oil price varies around the average (for $\tau=0.5$ or 0.6 ), strongly positive under bullish stock market condition $(\theta$ $=0.7,0.8)$ and when the oil price is low $(\tau=0.3)$ or highest $(\tau=0.9)$. We must point out that Venezuela is the most affected by oil price shock. Specifically, the oil price shock coefficient attains 3.0 when oil prices are at the top (for $\tau=0.9$ ). 
Regarding the magnitude, we show that the severity of oil shock effects on equities is not uniform across oil importing and oil exporting countries. Specifically, for oil exporting countries, Venezuela, Russia, and Saudi Arabia (in this order) are more vulnerable to oil price shocks than Kuwait, Norway, Mexico, and Canada. Focusing now on the case of oil importers, Japan, India, France, the US, and Germany (in this hierarchy) suffered most from untoward oil price shocks, while China and the UK experienced puny influence.

Figure 3. QQR estimates: Responses of stock returns to oil price shocks

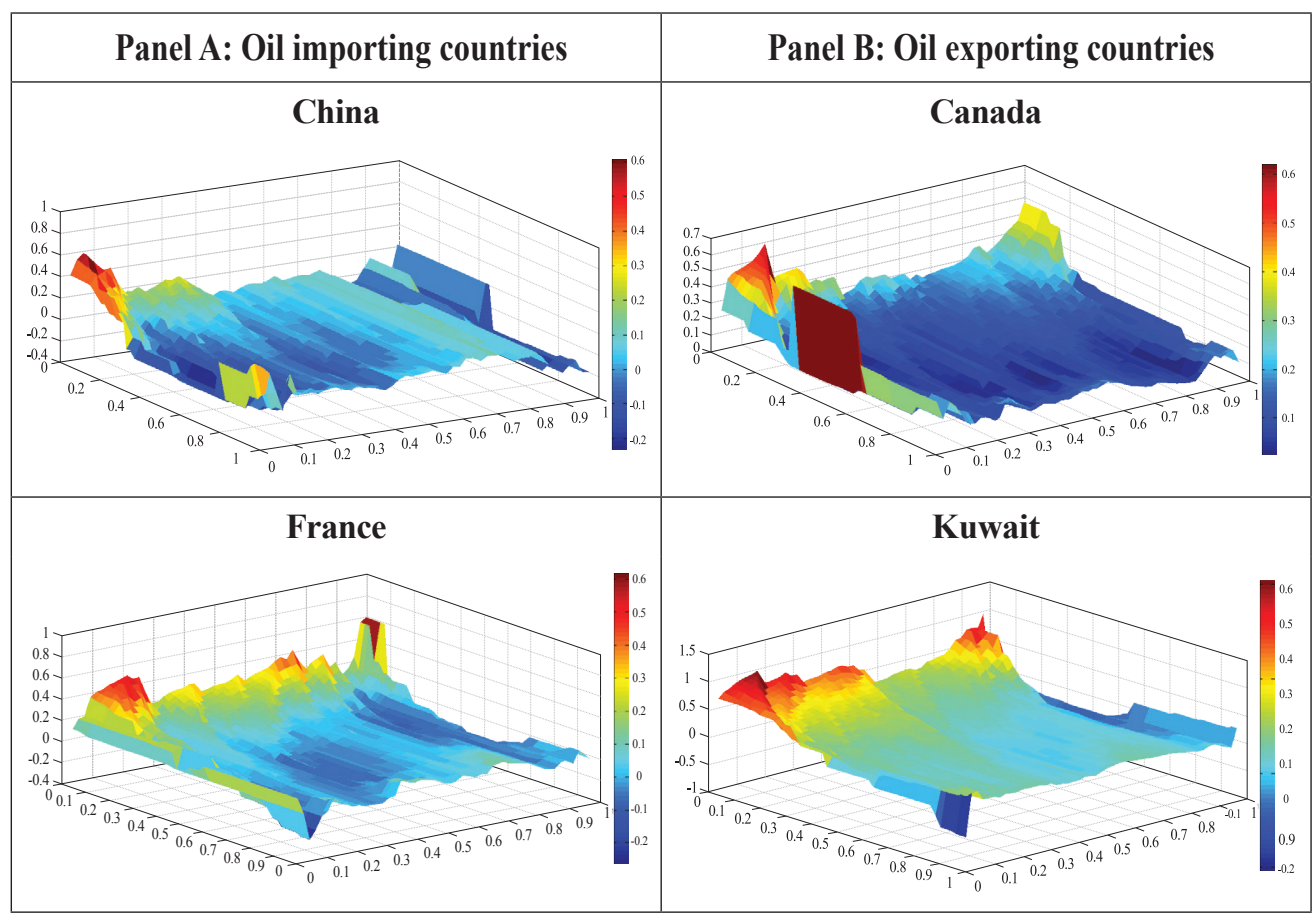




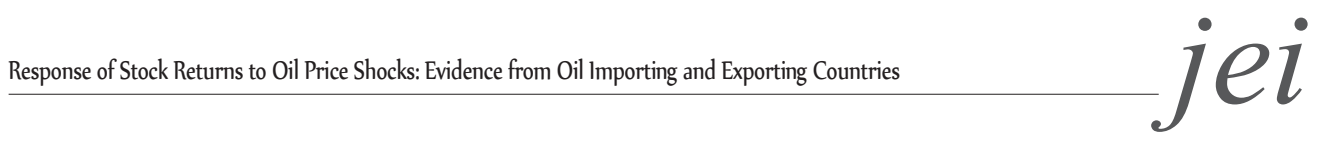

(continued)

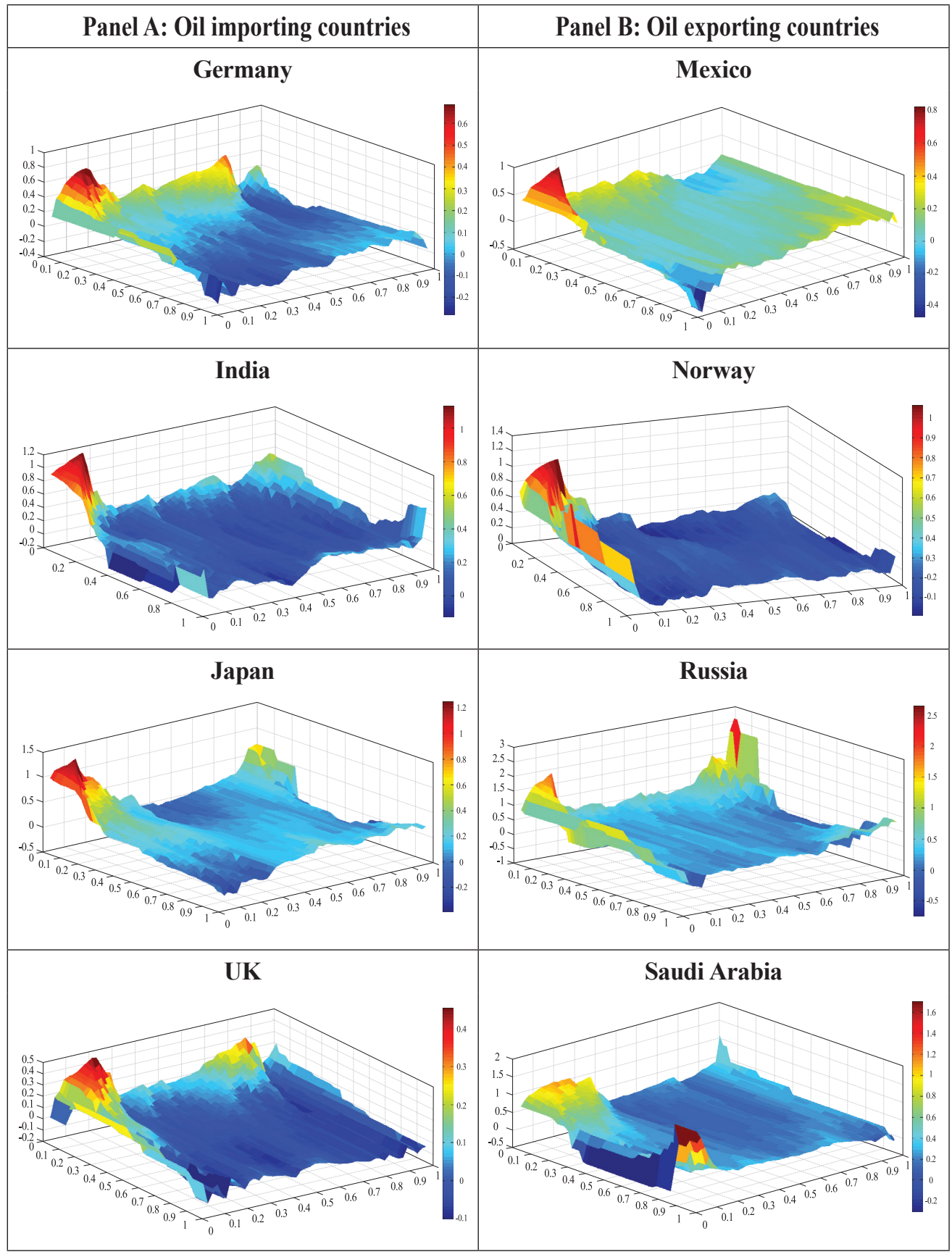


(continued)

\begin{tabular}{|c|c|c|c|}
\hline Panel A: Oil importing countries & Panel B: Oil exporting countries \\
\hline US & Venezuela \\
\hline
\end{tabular}

(Note) $\theta$-quantile of stock returns (left side of figure); $\tau$-quantile of oil price shocks (right side of figure).

This graph depicts the estimates of the slope coefficient, $\beta 1(\theta, \tau)$, which is placed on the $\mathrm{z}$-axis against the quantiles of the stock returns $(\theta)$ on the $y$-axis and the quantiles of oil price shocks $(\tau)$ on the $x$-axis. The colors in the color bar measure the degree of the co-movement between the two variables under investigation. The red color corresponds to positive and growing values of the slope coefficient, wheres the blue color corresponds to negative and weaker values of the slope coefficient.

\section{Comparison}

In practice, a $\mathrm{QQR}$ aims at disentangling the standard quantile regression estimates so that they are specific parameters for the different quantiles of an exogenous variable. One shortcoming of the QR method relies in its ineffectiveness to capture dependence in its entirety. Although the $\mathrm{QR}$ approach can properly depict the heterogeneous responses of equities to oil price shocks pertaining to distinct stock returns quantiles, it overlooks the possibility that whether oil price is cheap or expensive might have a strong influence on the way oil price shocks and equities are interdependent. To check the efficacy of the QQR approach, this study attempts to compare QQR and QR estimates. Recall that while the standard QR regresses the $\theta$-quantile of stock market returns on the oil demand shocks, the QQ regresses the $\theta$-quantile of stock market returns on the $\tau$-quantile of oil demand shocks; hence, its estimates are indexed by both $\theta$ and $\tau$. Notably, this double indexing allows gaining fresh insights and more disaggregated information on the convoluted relationship between oil shocks and stock returns.

As mentioned, the decomposition characteristics of the QQR model can be viewed as a special case of standard quantile regression. To recover the $\mathrm{QR}$ estimates from the 
QQR estimates, it must be recalled, first, that for $\mathrm{QR}$, the estimates are indexed by $\theta$ only. Thus, to properly construct parameters from the QQR model that are indexed by $\theta$, the estimated QQR parameters will be displayed by averaging along $\tau$. Hence, the effect of oil demand shocks on the distribution of stock returns, denoted by $\hat{\gamma}_{1}(\theta)$, can be obtained as follows:

$$
\hat{\gamma}_{1}(\theta)=1 / s \sum \hat{\beta}_{1}(\theta, \tau)
$$

where $s=45$ is the number of quantiles $\tau=[0.02,0.04, \ldots, 0.98]$ considered.

The validity of the QQR method, therefore, can be evaluated by comparing the quantile regression estimates with the $\tau$-averaged QQR parameters.

Figure 4. QR vs. average $Q Q R$ analysis

\begin{tabular}{|c|c|c|c|}
\hline \multicolumn{2}{|c|}{ Panel A: Oil importing countries } & \multicolumn{2}{c|}{ Panel B: Oil exporting countries } \\
\hline China & \multicolumn{2}{c|}{ Canada } \\
\hline
\end{tabular}


(continued)

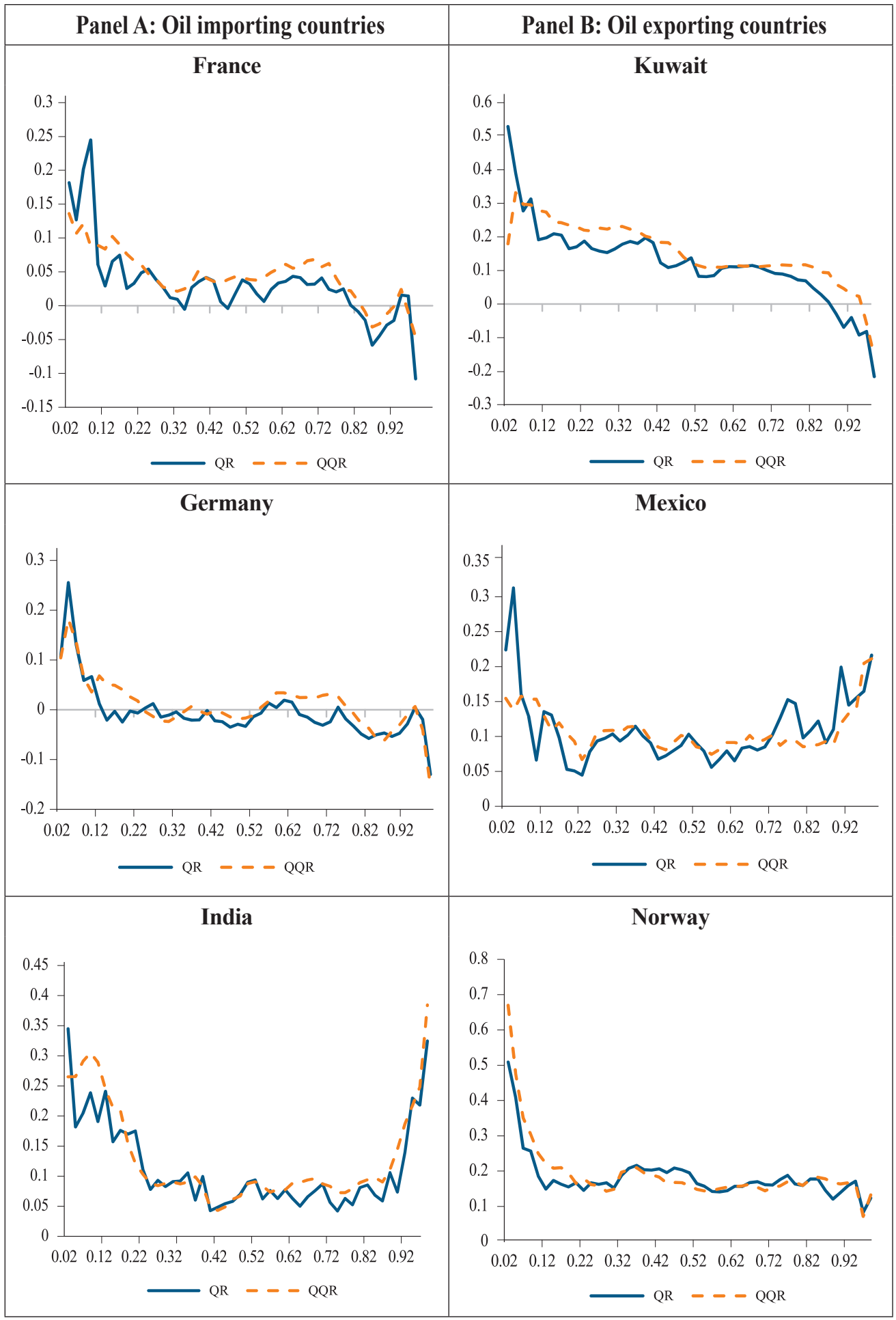


(continued)

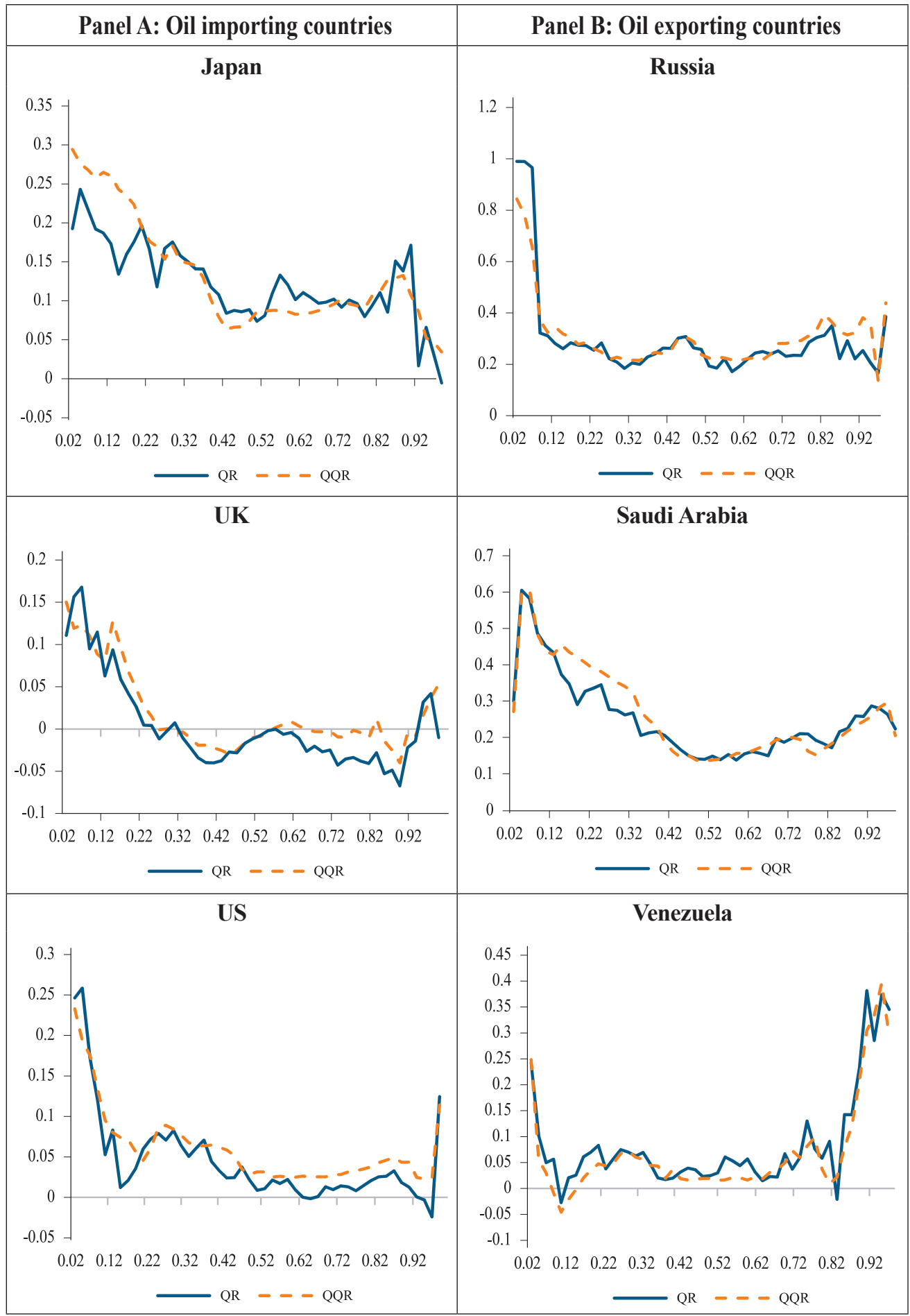

(Note) The slope coefficient that measures the impact of oil demand shocks on stock market returns over oil importers (Panel A) and oil exporters (Panel B).

(Source) Model results. 
Figure 4 plots the quantile regression and averaged QQR estimates of the slope coefficient that measures the impact of oil demand shocks on stock market returns (i.e., $\hat{\gamma}_{1}(\theta)$ ) over oil importers (Panel A, Figure 4) and oil exporters (Panel B, Figure 4). Irrespective of the nature of countries including oil importing or exporting, we clearly notice that the averaged QQR estimates of the slope coefficient are very similar to the quantile regression estimates, regardless of the considered quantile. This graphical evidence provides a simple validation of the QQR methodology by showing that the main features of the quantile regression model can be recovered by summarizing the more detailed information contained in the QQR estimates. However, QQR may provide better paths about the STR-Oil linkage than QR because the latter ignores the possibility that whether oil price is lower or higher could significantly affect the dynamic dependencies between stock returns and oil shocks.

\section{Conclusion}

Even though the hypothesis that external shocks significantly impact stock returns has enthralling appeal, it lacks robust empirical support. Because global investors increasingly use portfolio diversification as an effective strategy to lighten risks, a rigorous investigation of the stocks' responses to oil price shocks may be of paramount relevance for investors' optimal asset allocation decisions. This study uses a QQR approach to model the dependence structure between oil price shocks and stock returns from a new perspective. This new technique enables to capture the entire quantile dependence structure across different stock market conditions (i.e., bear, normal or bull market) and various kinds of oil prices (low, normal or high) while taking into account the origin of oil shocks. For fourteen oil importing and exporting countries, quite interesting findings were drawn. Beyond the nuance of asymmetry, QQR views those stocks' reactions to demand-side oil shocks to differ according to different stock market scenarios and diverse oil price levels. Potentially, we suggest that the differentiation between a net oil importer and a net oil exporter is heavily important when studying the effects of oil price shocks on the performances of stock markets. While oil importers typically undergo a modest reaction to sudden oil shocks (in particular, China and the $\mathrm{UK})$, the impact is seemingly more pronounced for oil exporting countries that possess 
vast proven oil reserves. Specifically, Venezuela, Russia, and Saudi Arabia, in that order, appear the most concerned by oil price changes driven by global oil demand shocks.

The obtained results underscore that during times of economic turmoil, the oil cannot serve as a safe haven that protect investors against risks and extreme losses in their stock market portfolios. Indeed, any attempt to diversify stock market risk using the oil market would not contribute to beneficial consequences for investors. Therefore, investors will have to see other commodities.

Interestingly, these findings can be used for portfolio construction and diversification as variant sensitivities to oil price shocks have been discovered across the considered equities. The fact that the reactions of stock returns to oil price shocks vary from lower to higher quantiles and across oil importers and exporters may have profound consequences for portfolios that trade with various rebalancing horizons. Diversifying portfolio investment will undoubtedly play a significant role on risk management. More accurately, a smallest vulnerability to oil shocks may be reached by allocating investment among different oil-dependent countries that would each react distinctly to oil price shocks. Although this does not guarantee against loss, portfolio diversification remains the most useful tool for achieving long-range financial goals while reducing untoward risks.

Last but not least, this paper may serve as a guide for market participants as it allows them to appropriately anticipate how the stock market reacts to oil price shocks while considering different stock markets scenarios, various kinds of oil price movements, and the origin of oil price shocks. It provides precise inflection points (depending to the quantiles of stock returns $(\theta)$ and oil price shocks $(\tau)$ ), which allows an adequate judgement of market structure in relation to entry and exit decisions. Digging further into the financial stability implications of the rising dependence of oil price shocks and stock returns while distinguishing between oil importers and exporters is a relevant issue for future research.

Received 2 October 2017, Revised 27 October 2017, Accepted 09 November 2017 


\section{References}

Al Janabi, M.A.M., Hatemi, J.A., and Irandoust, M. "An empirical investigation of the informational efficiency of the GCC equity markets: evidence from bootstrap simulation," International Review of Financial Analysis 19 (2010): 47-54.

Apergis, N. and Miller, S. M. "Do Structural Oil-market Shocks Affect Stock Prices?" Energy Economics 31 (2009): 569-575.

Barsky, R.B. and Kilian, L. "Oil and the macroeconomy since the 1970s," Journal of Economic Perspectives 18 (2004): 115-134.

Bouoiyour, J. and Selmi, R. "Testing for Frequency Causality between Oil Price and BRICS Stock Markets: A Comparative Analysis," Journal of Economic Integration 31 no.3, (2016): 547-568.

Bouoiyour, J. and Selmi, R. "The infernal couple China-Oil Price and the Responses of G7 Equities: A QQ Approach,” Working paper (2016), CATT, University of Pau.

Broadstocka, D.C. and Filis, G. "Oil price shocks and stock market returns: New evidence from the United States and China," Journal of International Financial Markets, Institutions and Money 33 (2014): 417-433.

Huang, R., Masulis, R.W. and Stoll, H.R. "Energy Shocks and Financial Markets," Journal of Futures Markets 16 (1996): 1-27.

Jammazi, R. and Nguyen, D.K. "Responses of international stock markets to oil price surges: a regime-switching perspective," Applied Economics (2015), DOI: 10.1080/00036846.2015.1030566.

Jones, C.M. and Kaul, G. "Oil and the Stock Market," Journal of Finance 51 (1996): 463-491.

Kilian, L. "The economic effects of energy price shocks," Journal of Economic Literature 46 (2008): 871-909. 
Kilian, L. "Not all oil price shocks are alike: disentangling demand and supply shocks in the crude oil market," American Economic Review 99 (2009): 1053-1069.

Kilian, L. and Park, C. "The impact of oil price shocks on the U.S. stock market," International Economic Review 50 (2009): 1267-1287.

Koenker, R. and Bassett, G. “Regression quantiles,” Econometrica 46 (1978): 33-50.

Koenker, R. and Xiao, Z. "Inference on the quantile regression process," Econometrica 81 (2002): 1583-1612.

Koenker, R. and Xiao, Z. "Quantile autoregression," Journal of the American Statistical Association 101 (2006): 980-990.

Le, T-H. and Chang, Y. "Effects of oil price shocks on the stock market performance: Do nature of shocks and economies matter?” Energy Economics, 51 (2015): 261-274.

Maghyereh, A. "Oil price shocks and Emerging stock markets: A generalized VAR Approach," International Journal of Applied Econometrics and Quantitative Studies 1(2004).

Narayan, P.K. and Narayan, S. "Modelling the impact of oil prices on Vietnam's stock prices," Applied Energy 87 (2010): 356-361.

Ma, L. and Koenker, R. "Quantile regression methods for recursive structural equation models," Journal of Econometrics 134 (2006): 471-506.

Ono, S. "Oil price shocks and stock markets in BRICs," European Journal of Comparative Economics 8 (2011): 29-45.

Papapetrou, E. “Oil Price Shocks, Stock Market, Economic Activity and Employment in Greece," Energy Economics 23 (2001): 511-532.

Park, J. and Ratti, R.A. "Oil price shocks and stock markets in the US and 13 European countries," Energy Economics 30 (2008): 2587-2608.

Sadorsky, P. “Oil price shocks and stock market activity,” Energy Economics 21 (1999): 449-469. 
Shimon, A. and Raphael, S. "Exploiting the Oil-GDP effect to support renewable development," Energy Policy 34 (2006): 2805-2819.

Sim, N. and Zhou, A. "Oil prices, US stock return, and the dependence between their quantiles," Journal of Banking \& Finance 55 (2015): 1-8.

Wang, Y., Wu, C. and Yang, L. "Oil price shocks and stock market activities: Evidence from oil-importing and oil-exporting countries," Journal of Comparative Economics 41 (2013): 1220-1239. 